\title{
Energy Savings by Treating Buildings as Systems
}

\author{
L.D. Danny Harvey \\ Department of Geography \\ University of Toronto \\ 100 St George Street \\ Toronto, M5S 3G3, Canada
}

\begin{abstract}
This paper reviews the opportunities for dramatically reducing energy use in buildings by treating buildings as systems, rather than focusing on device efficiencies. Systemslevel considerations are relevant for the operation of heat pumps (where the temperatures at which heat or coldness are distributed are particularly important); the joint or separate provision of heating, cooling, and ventilation; the joint or separate removal of sensible heat and moisture; and in the operation of fluid systems having pumps. Passive heating, cooling, and ventilation, as well as daylighting (use of sunlight for lighting purposes) also require consideration of buildings as systems. In order to achieve the significant (50-75\%) energy savings that are possible through a systems approach, the design process itself has to involve a high degree of integration between the architect and various engineering disciplines (structural, mechanical, electrical), and requires the systematic examination and adjustment of alternative designs using computer simulation models.
\end{abstract}

\section{INTRODUCTION}

The energy use of buildings depends to a significant extent on how the various energy-using devices (pumps, motors, fans, heaters, chillers, and so on) are put together as systems, rather than depending on the efficiencies of the individual devices. The savings opportunities at the system level are generally many times what can be achieved at the device level, and these system-level savings can often be achieved at a net investment- cost savings. Thus, by failing to analyze buildings as systems, the energy savings potential in the building sector will be vastly underestimated, costs will be overestimated, and, as a result, less stringent policies with regard to energy use and greenhouse gas emissions from this sector will be adopted than if policymakers are fully aware of the systems-level savings potential. At the same time, the systems-level analysis presents a greater intellectual challenge to building designers than analyses at the device level, but the large efficiencies achievable at the system level provide a greater motivation for work at the systems 
level. The purpose of this paper is to provide examples of how system-level considerations lead to large energy savings opportunities in the buildings sector.

\section{SYSTEM-LEVEL CONSIDERATIONS FOR MECHANICAL SYSTEMS}

\section{Heat Pumps, Operating Principles}

Heat pumps provide a simple example of the difference between system and device efficiency. A heat pump transfers heat from cold to warm (against the macro temperature gradient), although at each point in the system, heat flow is from warm to cold. It relies on the fact that a liquid cools when it evaporates, and the cooling effect is greater the lower the pressure of evaporation, while a gas releases latent heat as it condenses and is warmed to a greater temperature the greater the pressure. The key energy-using device in a heat pump is a compressor, which increases the pressure of the working fluid on the discharge side and creates low pressure on the suction side. The cycle during heating mode is illustrated in Figure 1a. As the working fluid is compressed, it is heated to a temperature in excess of the indoor air temperature. This allows heat to be transferred to the indoor air stream in an indoor heat exchanger, thereby extracting heat from (and condensing) the refrigerant. The more the gas is compressed (i.e., the greater the pressure), the more it warms up. The liquid refrigerant travels through an expansion valve to a heat exchanger that is connected to the suction side of the compressor. The low pressure there induces evaporation and hence cooling of the refrigerant. The lower the pressure, the greater the cooling that occurs. The refrigerant must by cooled to below the temperature of the outdoor air in order to absorb heat from the outside air. The cool, low-pressure refrigerant, now in the gaseous state, returns to the compressor, where the cycle is repeated.

By simply reversing the direction of fluid flow, a heat pump can act either as a heating unit (transferring heat from the outside to inside) or as an air conditioner (transferring heat from the inside to outside). This is illustrated in Figure 1b. An air conditioner is a heat pump that operates in only one direction.

The efficiency of a heat pump is represented by its coefficient of performance (COP), which is the ratio of heat delivered to energy input. The difference between the temperatures of the evaporator and condenser is called the temperature lift. The maximum possible COP (called the Carnot cycle COP) pertains to an ideal (fully reversible) heat pump, and is related to the temperature lift as follows:

$$
C O P_{\text {cooling,ideal }}=\frac{T_{L}}{T_{H}-T_{L}}
$$

and

$$
C O P_{\text {heating,ideal }}=\frac{T_{L}}{T_{H}-T_{L}}+1.0
$$


where $T_{L}$ is the evaporator (lower) temperature and $T_{H}$ is the condenser (higher) temperature. The Carnot COP for heating is equal to the Carnot COP for cooling plus 1.0 because the energy input to the heat pump is ultimately dissipated as heat and so adds to the heat that can be supplied.

(a) Heating Mode

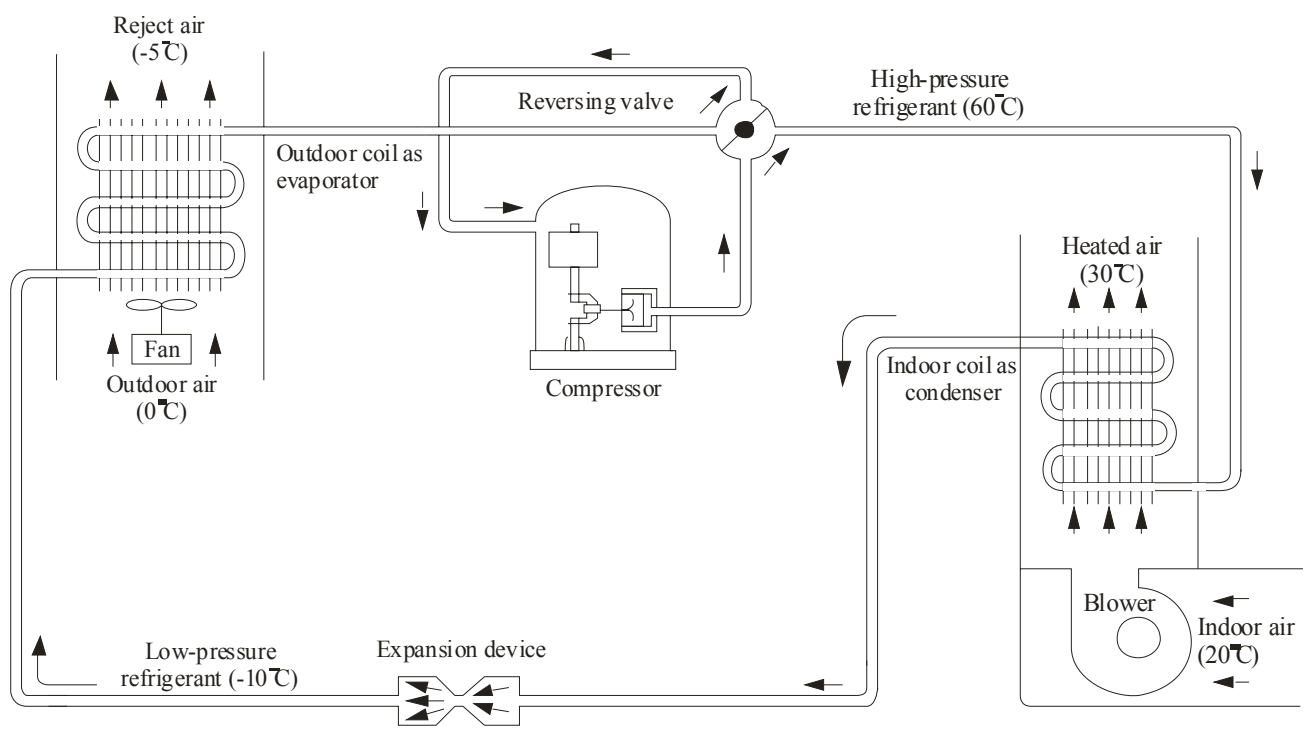

(b) Cooling Mode

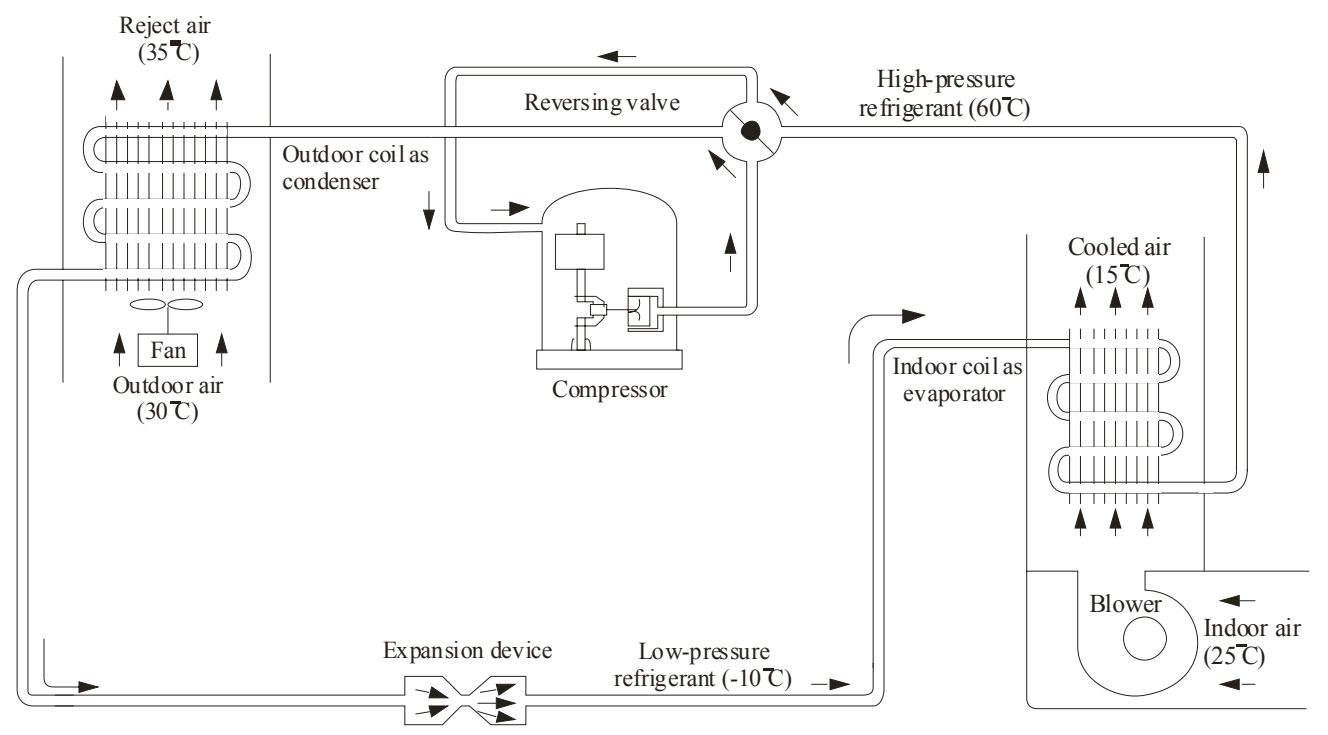

FIGURE 1. Refrigerant flow in a heat pump operating in heating mode (upper panel) and cooling mode (lower panel). Source: (1). 
The actual COP is given by

$$
C O P_{\text {cooling, real }}=\eta_{c}\left(\frac{T_{L}}{T_{H}-T_{L}}\right)
$$

where $\eta_{\mathrm{c}}$ is the Carnot efficiency. A typical Carnot efficiency is around $65 \%$. If one focuses on the device efficiency, one might imagine increasing the efficiency to $75 \%$, which would reduce the energy use by only $14 \%$. However, if one can reduce the temperature lift required for given heating or cooling load, then vastly greater reductions in energy use are possible.

The evaporator must be colder than the heat source in order to draw heat from it, and the condenser must be warmer than the heat sink in order to supply heat to heat. The relationships are shown in Figure 2 for the case of heat source and sink temperatures of $16^{\circ} \mathrm{C}$ to hot water at $30^{\circ} \mathrm{C}$, with temperature differentials of $10 \mathrm{~K}$ at both the evaporator and condenser. The apparent lift, based on the heat source and sink temperatures, is $14 \mathrm{~K}$, and the apparent Carnot COP is 20.6. However, the real lift and real Carnot COP are $34 \mathrm{~K}$ and 8.5, respectively. The real COP, given a Carnot efficiency of 0.65 , would be 5.53 . However, if both temperature differentials are cut in half, the COP would increase to 7.75 , a $40 \%$ improvement.

There are two ways to increase the real COP: to reduce the apparent lift by reducing the difference between the heat source and sink temperatures, and to further reduce the real lift by reducing the temperature differentials. The temperature differentials can be reduced by (i) reducing the required heat flux, (ii) building larger heat exchangers, or (iii) designing the heat exchangers to be more effective in transferring heat for a given area and temperature difference. The temperature differential is the driving force for the heat flow, so with smaller required heat flows, the temperature differentials do not need to be as large. In heating mode, the heat flow from the condenser must balance the heat loss from the building, so a highperformance thermal envelope (high levels of insulation, windows with low heat loss) will permit more efficient operation of the heat pump by permitting a smaller real temperature lift. Similarly, measures that reduce heat gains in a building (a highperformance thermal envelope and efficient lighting and equipment to minimize internal heat gains) will permit a more efficient cooling heat pump (or more efficient air conditioners or chillers).

The apparent temperature lift can be reduced by distributing heat at the coolest possible temperature or distributing coldness at the warmest possible temperature. In buildings with hydronic cooling (that is, where coldness is distributed via cold water), it is common to distribute coldness at a temperature of $6-8^{\circ} \mathrm{C}$. This would require an evaporator temperature of $0^{\circ} \mathrm{C}$ or less, while the condenser might be at a temperature of $50^{\circ} \mathrm{C}$, so as to discharge sufficient heat to the surrounding air. The cooling units usually involve a small coil with a fan in the rooms that need to be cooled. However, temperatures as warm as $20^{\circ} \mathrm{C}$ can provide adequate cooling if the entire ceiling is 
cooled by circulating the cooling water through panels mounted on the ceiling (illustrated in Figure 3) or inside the concrete core of the ceiling. This permits a much warmer evaporator, a smaller temperature lift, and hence a larger COP. Similarly, distributing heat at the coolest possible temperature minimizes the temperature lift required in heating mode. Low heating temperatures are possible if the entire ceiling or floor is heated and serves as a radiator.

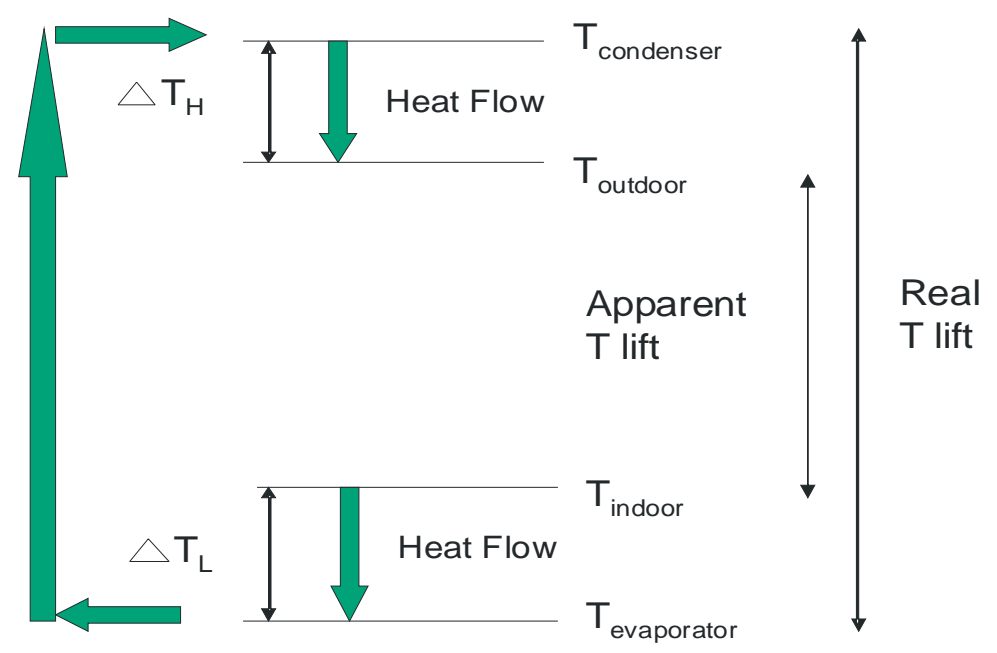

FIGURE 2. Relationships between real and apparent temperature lifts, temperature differentials $\left(\Delta \mathrm{T}_{\mathrm{L}}\right.$ and $\left.\Delta \mathrm{T}_{\mathrm{H}}\right)$, and heat flow in a heat pump.

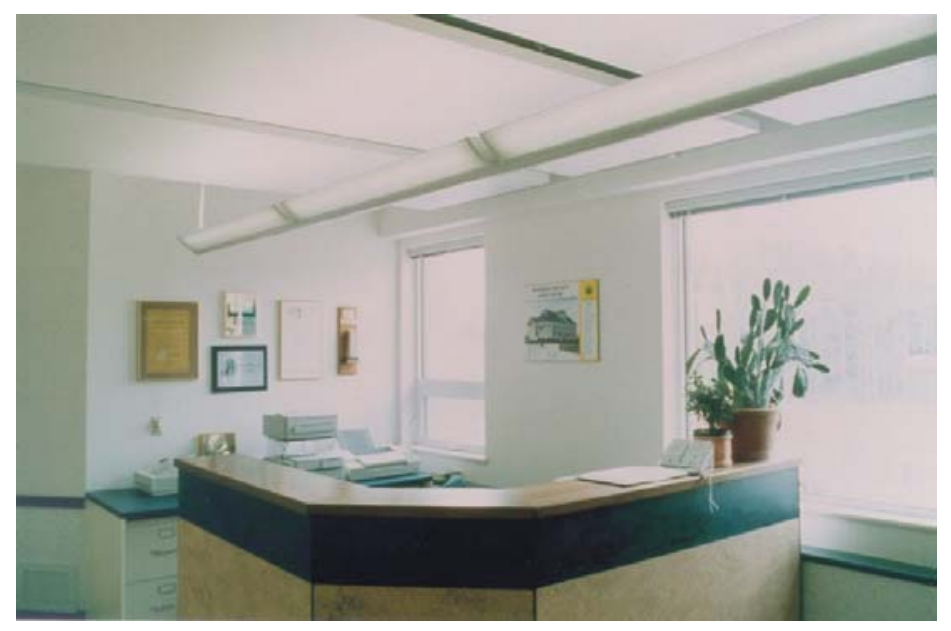

FIGURE 3. A chilled ceiling panel. Source: www.advancedbuildings.org. 

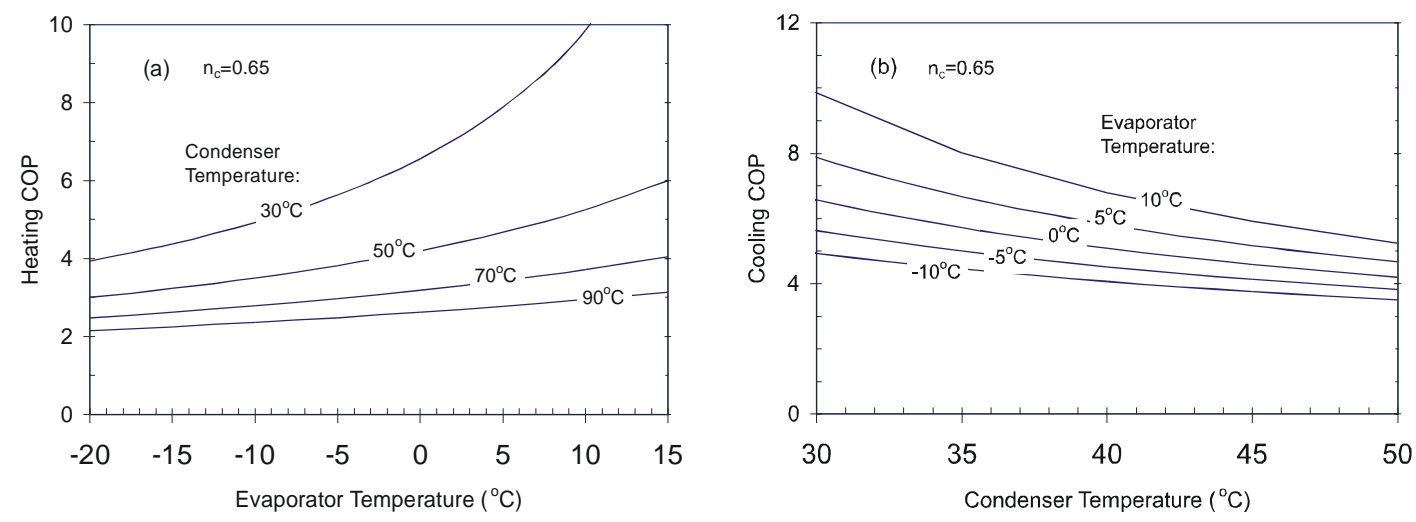

FIGURE 4. Variation in the COP of a heat pump in heating mode and in cooling mode for various evaporator-temperature combinations, assuming a Carnot efficiency of 0.64 . Source: (1).

The other way to reduce the apparent temperature lift is to draw heat from the warmest possible temperature source in heating mode (such as the ground or exhaust airflow, rather than from cold outside air), and to reject the heat to the coolest possible heat sink in air conditioning mode (such as to evaporatively cooled water, the ground, or lake, river, or sea water rather than to the hot outside air). Figure 4 shows the variation in the COP of a heat pump in heating mode and in cooling for various evaporator-temperature combinations. There can frequently be a factor of two difference in the heat pump COP between best-case and worst-case combinations of evaporator and condenser temperature.

\section{Heating, Ventilation, and Air Conditioning (HVAC) Systems}

The combined heating, ventilation, and air conditioning systems (HVAC systems) in buildings present many opportunities for large reductions in energy use through better integration of the system components. These components might be air conditioners or chillers (which produce cold water), pumps, fans, cooling towers, and various devices for exchanging heat and possibly moisture from one airstream to another.

\section{Separation of ventilation from heating \& cooling functions}

In many buildings, air is circulated both for ventilation purposes (to deliver fresh air) and for heating and cooling. However, the airflows usually required in order to deliver adequate heat or coldness (without unduly warm or cold supply air) are usually several times greater than the airflows required for ventilation purposes. If heat or coldness are instead delivered by circulating warm or cool water, the required airflows can be greatly reduced. This in turn leads to a large savings in fan+pump energy use, because delivering heat or coldness by moving water is inherently more efficient than by moving air. Further large reductions in fan energy use are possible if the ventilation airflow can be reduced through more effective ventilation, and if ventilation is avoided 
or greatly when it is not needed (which is possible if heating and cooling are independent of ventilation).

The power that must be imparted to a moving fluid in order to sustain its motion is given by

$$
\mathrm{P}_{\text {fluid }}=\Delta \mathrm{P} \times \mathrm{Q}
$$

where $\Delta \mathrm{P}$ is the pressure head created by the fan or pump (and is equal to the sum of all the pressure losses through the flow circuit) and Q is the volumetric flow rate. The rate at which heat is given off (in Watts) by an air or water flow, $\mathrm{Q}_{\mathrm{H}}$, is given by

$$
Q_{H}=\rho c_{p} Q\left(T_{\text {sup ply }}-T_{\text {return }}\right)=\rho c_{p} Q \Delta T
$$

where $\rho$ and $c_{p}$ are the fluid density and specific heat, respectively. From Eqs. (4) and (5), the ratio of energy supplied to keep a fluid moving to heat removed or supplied by the fluid flow is given by $\Delta \mathrm{P} / \rho \mathrm{c}_{\mathrm{p}} \Delta \mathrm{T}$. Given typical $\rho, \mathrm{c}_{\mathrm{p}}$, and $\Delta \mathrm{T}$ values for hydronic and air systems, it turns out that the energy used to deliver a given amount of heat or coldness is about 25 times less using water than using air (1, Section 7.1.2).

The electric power that must be supplied to the fan or pump used to push the fluid is given by

$$
P_{\text {electric }}=\frac{\Delta P Q}{\eta_{m} \eta_{p}}
$$

where $\eta_{\mathrm{m}}$ and $\eta_{\mathrm{p}}$ are the motor and pump (or fan) efficiencies, respectively. As $\Delta \mathrm{P} \alpha$ $\mathrm{Q}^{2}$ for turbulent flow,

$$
\mathrm{P}_{\text {fluid }} \alpha \mathrm{Q}^{3}
$$

Thus, cutting the required rate of flow in half reduces the required rate at which energy needs to be supplied to the flow by a factor of 8 . Motor and pump efficiencies decline slightly at lower flow rates, but the electrical energy requirement still decreases by a factor of 6-7. For this reason, it is far more effective to deliver heat and coldness by circulating warm or cold water, with the airflow reduced to the much smaller flow rates needed for ventilation purposes alone. Further savings are possible if the ventilation airflow requirements are themselves reduced through more effective delivery of ventilation air to the breathing zone, as discussed next.

\section{Displacement ventilation}

Ventilation air flow requirements can be reduced by a factor of two by using displacement ventilation (DV) rather than ceiling-based mixing ventilation, while improving air quality and reducing total heating loads on the chillers. DV involves supplying slightly cooled ventilation air at floor level (or from small, scattered diffusers in the floor itself), then relying on internal heat gains to heat the ventilation 
air, causing it to gradually rise and displace the room air, and then exit through ceiling vents. This is in contrast to conventional systems, where fresh air is supplied at ceiling level, and reliance is placed on diluting rather than displacing the stale room air through turbulent mixing. DV is inherently more efficient than mixing ventilation, and saves energy by permitting a factor-of-two reduction in ventilation air flow and by permitting the supply of air at warmer temperatures (due in part to the fact that heat that accumulates in the ceiling area is directly removed from the room rather than mixed it into the room air). When combined with chilled ceiling cooling (described below), a savings of 40-60\% in cooling energy use occurs in various US cities compared to a standard mixing ventilation system with variable airflow (2-5).

\section{Chilled ceiling and cooling towers for direct evaporative cooling}

The natural complement to DV is chilled ceiling (CC) cooling, in which cooling water at $16-20^{\circ} \mathrm{C}$ is circulated through large ceiling panels. Conventional systems provide chilled water at a temperature as low as $6-8^{\circ} \mathrm{C}$ (and generally no warmer than $14^{\circ} \mathrm{C}$ ). There are a number of energy-saving synergies with $\mathrm{CC}$ cooling:

- the room temperature can be $2 \mathrm{~K}$ warmer with the same perceived temperature, which will reduce heat gains due to conduction and leakage through the building envelope; and

- by providing cooling at $16-20^{\circ} \mathrm{C}$, the chiller efficiency will be much larger (as noted earlier) or the chiller can be bypassed altogether if the coolingtower water is used for chilling (as discussed below).

However, if a chilled ceiling is combined with an otherwise conventional system, both of these energy savings can be lost. In particular,

- $\quad$ if dehumidification is accomplished by over-cooling the ventilation air and then reheating it, more energy will be needed for reheating because the ventilation air is supplied at a warmer temperature in a CC system;

- $\quad$ if ice thermal storage is used in order to shift some of the cooling load from daytime to night-time, then the COP benefit of a warmer chilled-water temperature and the greater opportunity for directly cooling the chilling water using the cooling tower are lost, because initial cooling down to freezing occurs (a partial solution for storing coldness is to use materials, such as eutectic salts, with a warmer freezing point).

Thus, the magnitude (and even the sign) of the change in energy use from a given design change can depend on the other parts of the system.

In most HVAC systems, a cooling tower (shown schematically in Figure 5) is used to provide water at $20^{\circ} \mathrm{C}$ or less through evaporative cooling. This evaporativelycooled 


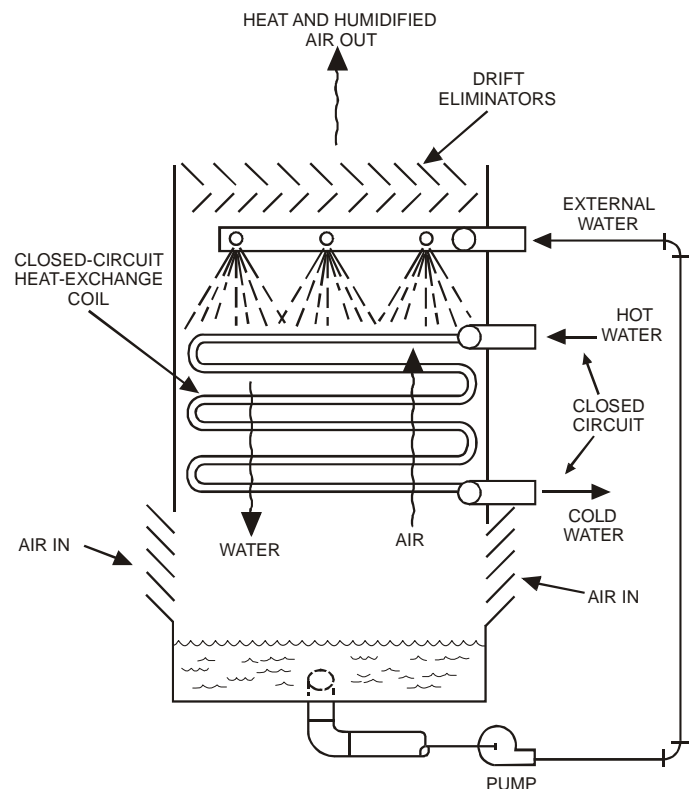

FIGURE 5. Schematic illustration of a cooling tower. Source: (1).

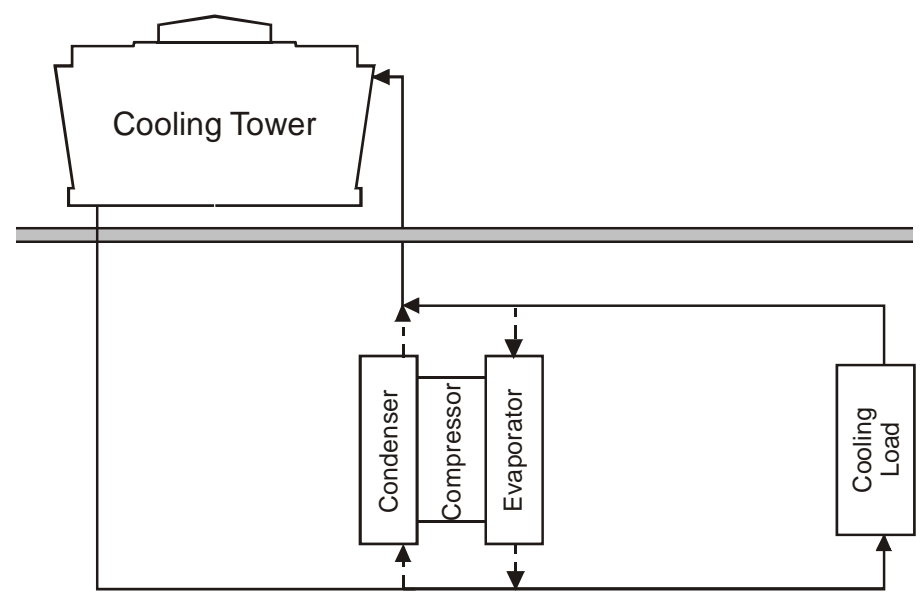

FIGURE 6. Cooling tower used as an evaporative chiller. Under normal operation, the cooling tower water would circulate through the condenser only (removing heat from the condenser) and building cooling water would circulate through the evaporator (as shown by dashed lines). In free cooling mode, the condenser and evaporator would be bypassed altogether and the compressor shut off. Modified from (1).

water is used for removing heat from the chiller condenser, permitting a lower condenser temperature than if it were cooled with ambient air. However, when cooling is provided with $18-20^{\circ} \mathrm{C}$ water in ceiling panels, the cooling tower water will often be cool enough to be directly used for cooling purposes, bypassing the chiller altogether and greatly reducing the required energy. This arrangement is illustrated in Figure 6. Assuming the chilling water to be supplied at $18^{\circ} \mathrm{C}$, a cooling tower could directly meet cooling requirements $97 \%$ of the time in Dublin and $67 \%$ of the time in Milan 
according to (6). If chilling water at $20^{\circ} \mathrm{C}$ is adequate, then evaporative cooling in a cooling tower is sufficient $99 \%$ of the time in Dublin and $78 \%$ of the time in Milan.

\section{Dedicated outdoor air systems}

As noted above, heat and coldness are delivered in many systems HVAC systems solely by circulating warm or cool air, but the amount of air that is circulated is many times that needed for ventilation purposes alone. So as to reduce the volume of outside air that needs to be heated and humidified (in winter), or cooled and dehumidified (in summer), it is common to recirculate, say, $80 \%$ of the indoor air on each circuit, while exhausting only $20 \%$ and replacing the exhausted air with fresh outside air. However, this means that $80 \%$ of the internal heat gains picked up by the moving air will have to be removed by the chiller. However, if heating/cooling and ventilation functions are separated, then the amount of air that is circulated can be reduced to that needed for ventilation alone. All of the air will then have to be directly exhausted to the outside, producing a Dedicated Outdoor Air Supply (DOAS) system. If a DOAS system is combined with DV, then internal heat gains from lighting, and warm plumes that rise to the ceiling from office equipment, will be directly vented to the outside, reducing the cooling load on the chillers by up to $30 \%$ (7). Ventilation rates can be reduced to near zero when the building is not occupied (because ventilation is not used for temperature control). This is referred to as demand-controlled ventilation (DCV), and can save $20-30 \%$ in total heating+cooling+ ventilation energy use on an annual basis (8).

\section{Separating cooling and dehumidification functions}

The conventional approach in dehumidifying air is to cool it to a temperature of 6$8^{\circ} \mathrm{C}$, so as to condense out adequate water vapor, then to reheat the air to the desired supply-air temperature (typically $12-14^{\circ} \mathrm{C}$ ). This is inefficient because (i) the chillers must operate with a lower evaporator temperature than if the air were directly cooled to the supply-air temperature, (ii) greater cooling is carried out, and (iii) subsequent reheating is required. The inefficiency would be greater in a DV system because the supply-air in such systems is $16-18^{\circ} \mathrm{C}$, so greater reheating from the same cold temperature would be required. An alternative is to directly remove water vapor using passive or active desiccant wheels. Both consist of a rotating drum that contains a solid desiccant and rotates from the incoming airflow (picking up moisture) to the outgoing airflow (releasing moisture) and back. In a passive desiccant wheel, the dryness of the outgoing airflow is the driving force for driving moisture from the desiccant. In an active desiccant wheel, supplemental heating of the outgoing air stream is used to assist in driving moisture from the desiccant. The combination of active desiccant wheels with conventional (electric vapor-compression) cooling systems reduces electricity use both by shifting some of the cooling load (the latent portion) to the desiccant wheel, which in turn can be regenerated using solar thermal energy, and by permitting a higher chiller evaporator temperature and hence greater chiller COP. Total energy savings in cooling and dehumidification can vary from as little as $6 \%$ to almost $50 \%$, depending on the way the components of the system are 
put together, and up to $75 \%$ if solar thermal energy is used to regenerate the desiccant (9-11).

Desiccant wheels can be used to over-dry the incoming ventilation air, which then permits cooling through evaporative cooling without producing air that is too humid. In effect, desiccant systems extend the applicability of evaporative cooling into the hot-humid regions of the world, where it otherwise cannot be used. Air quality problems associated with moist evaporators are eliminated too.

An interesting synergy between different system components arises from the fact that the COP of a solid-desiccant cooling system increases with increasing initial temperature and humidity even though the regeneration temperature must be increased in order to produce the same final temperature and humidity (this is explained in 1 , Box 6.5). An important corollary is that the COP will be lower if the desiccant cycle is applied to outside air that has been mixed with recirculated indoor air (as in most conventional systems). This is another factor in favor of DOAS systems, but these require supplemental hydronic heating and cooling so as to avoid excessively large ventilation airflows.

A building envelope with less uncontrolled infiltration of outside air directly reduces both sensible and latent cooling loads, by reducing the amount of heat and moisture that enter the building. The reduced influx of outside moisture means that the ventilation air supply does not need to be dried as much, which in turn permits a lower desiccant regeneration temperature and more efficient operation of the desiccant system. If the desiccant is regenerated with solar heat, more solar heat can be collected and with fewer losses if can be supplied at a lower temperature. Thus, there are a number of interactions through which a better building envelope increases the efficiency of solar-desiccant systems.

\section{Pump systems}

A system as simple as a pump that circulates water through a circuit exhibits energy savings opportunities that are vastly greater than can be expected by improving the device (pump) efficiency. The rate of flow through a pump varies directly with the speed of the impeller's rotation and its diameter, while the pressure developed varies as the square of the impeller speed and the square of the impeller diameter. The pump would, ideally, be chosen such that the pressure head created at the desired flow rate exactly balances the pressure drop in the piping system. However, this does not happen in practice. This is because there are errors in the calculation of the pressure drop created by the piping network for a given flow rate, and multiple safety factors are routinely built into the calculations, so that the resulting flow is invariably greater than specified. Thus, after the pump has been installed, it has to be operated to determine the actual flow at the specified pump speed. The pump-piping system should then be "rebalanced" so that the desired flow is created (12). This is done as follows: A piping system will typically have many parallel circuits, and the relative flow errors will generally be different for each circuit. A control valve in each circuit will need to be slightly closed (thereby throttling the flow), but this should be done only to bring the ratio of actual flow to predicted flow down to the ratio found in the circuit with the smallest ratio (so no adjustment of the control valve is needed in this 
circuit). At that point, the pressure head developed by the pump can be reduced, thereby reducing the flow in each circuit and bringing them all simultaneously down to the design-flow. The net result is to achieve the desired flow in all circuits with a minimum of throttling.

The pressure head developed by the pump can be reduced by trimming the impellor inside the pump (which requires disassembling and re-assembling the pump), or by reducing the rotational speed of the impellor. However, even if excess flow is recognized, the pump is rarely adjusted to achieve the design-flow, especially if the system is operating smoothly.

To understand the implications for energy use by the pump, we need to examine the pressure-head/flow variation for both the pump and the piping system on a single diagram, as shown in Figure 7. The convex-upward curves show the variation of pressure head and flow rate for a variety of fixed impeller diameters (these are a characteristic of the particular pump). For a given impeller diameter, a greater flow rate (due to less resistance in the system to which the pump is connected) is associated with a smaller pressure head. The concave-upward curves show the variation of piping system pressure

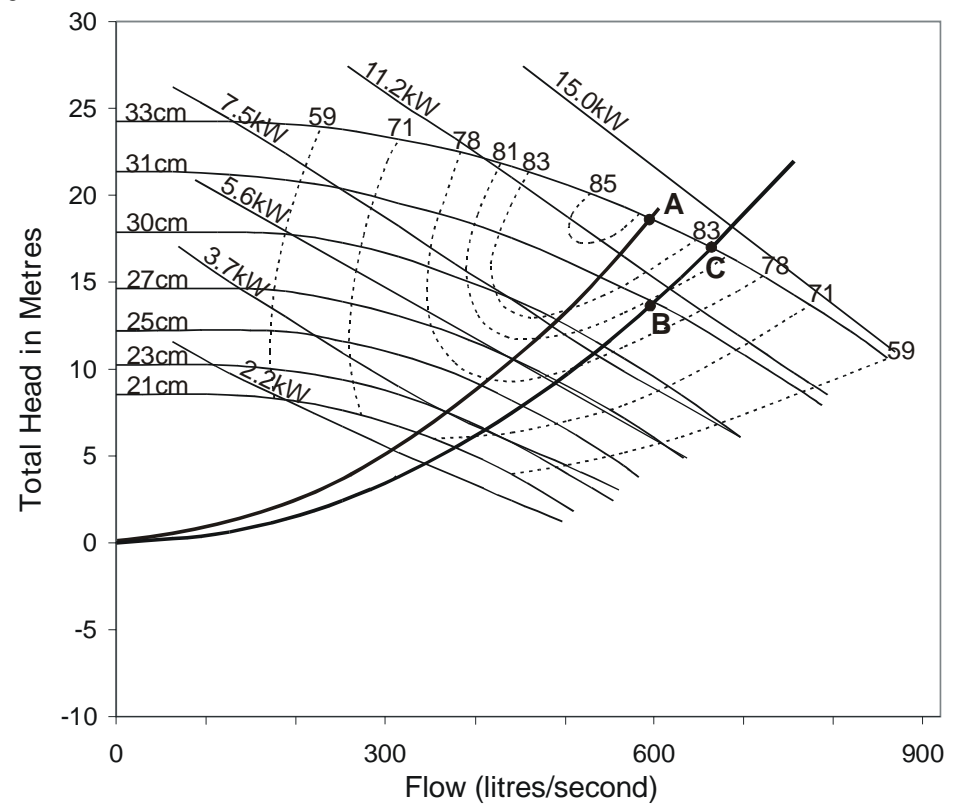

FIGURE 7. Pressure-flow relationship for a pump with different impellor diameters (convex upward curves) and for a piping system as originally estimated (upper concave up curve) and in reality (lower concave up curve). Point A: intended operating point. Point C: actual operating point without trimming the impellor - energy use is $6 \%$ larger. Pont B: operating point with impellor trim - energy use drops by $25 \%$ ! Source: (1).

drop with flow rate; one curve is the calculated relationship, and the other is the actual relationship for that particular system. Also shown in Fig. 7, as dashed lines, are contours of pump efficiency. Point " $\mathrm{A}$ " is the expected operating point. However, as is typically the case, the pressure drop for the desired flow is less than the computed pressure drop (due to various safety factors). This is represented by point " $B$ ". Since the pump generates more pressure than needed, flow increases, the pump pressure 
head decreases, the system pressure drop increases, and the two come into balance at point " $C$ ", but with excess flow. The fluid power $\left(\mathrm{P}_{\text {fluid }}\right)$, equal to the product of pressure head and flow, is essentially unchanged in this example. However, the pump would have been chosen so as to have the greatest efficiency near the design flow, and is somewhat less at the actual operating point. The net result is a $5.6 \%$ increase in pump energy use, and most systems would be allowed to operate in this manner. However, at point B (where the pump efficiency is even lower), the required pump power is $24 \%$ less than at point $\mathrm{C}$. This is not a negligible savings!

\section{Summary for HVAC Systems}

To sum up, to minimize the energy use in supplying and delivering heat or coldness and fresh air with mechanical systems, one should

- $\quad$ separate heating/cooling and ventilation functions by circulating hot or cold water for heating and cooling purposes;

- $\quad$ separate cooling and dehumidification functions by using desiccants for dehumidification;

- $\quad$ use chilled water at the warmest possible temperature for cooling (ideally, $20^{\circ} \mathrm{C}$ );

- use hot water for heating at the coolest possible temperature (ideally, $\left.30^{\circ} \mathrm{C}\right)$

- circulate only the amount of air required for ventilation purposes alone, varying with time based on actual needs, using displacement ventilation in a dedicated outdoor air supply system; and

- $\quad$ rebalance pumps and fans after cooling or heating circuits have been operated, so that they are attempting to do the least possible amount of work.

The minimization of temperatures used for heating requires large radiator surfaces (as in floor or ceiling radiant heating) and minimal heat loads, the latter requiring a high-performance envelope to minimize heat losses during the heating season. Similarly, maximization of temperatures used for cooling requires large radiator surfaces and minimal cooling loads, the requiring a high-performance thermal envelope and efficient equipment and lighting so as to minimize internal heat gains. Displacement ventilation (DV) works best if uncontrolled air flows (due to leaky building envelopes) are minimized. Thus, a high performance envelope saves energy both by directly reducing heating and cooling loads, by permitting alternative mechanical systems, and by permitting more efficient operation of conventional systems and equipment. Desiccant dehumidification avoids the need for overcooling and reheating of air for dehumidification, and will be most beneficial in combination with DV as one can take full advantage of the warmer supply-air temperature permitted with DV. Dedicated Outdoor Air Supply (DOAS) systems increase heating and cooling loads (and thus energy use) in a conventional all-air cooling system because large airflow rates are required in order to provide adequate heating and cooling without excessive supply temperatures, and all of this air is exhausted and 
replaced after one circuit in a DOAS system rather than partly recirculated. A system where air flow meets ventilation requirements only (with radiant heating and cooling for most of the heating and cooling loads) is, of necessity, a DOAS system and, when combined with DV, saves energy because waste heat from lights and other sources at ceiling level is directly vented to the outside.

\section{PASSIVE VENTILATION, HEATING, AND COOLING}

The focus thus far has been on mechanical HVAC systems. However, it is possible to design buildings to be passively heated, cooled, and ventilated. In this case, the building and its interaction with surrounding buildings through the outside airflow has to be understood and designed as an integrated fluid-dynamic and thermal system. In combination with a high-performance thermal element, the potential exists to completely eliminate the need for mechanical ventilation and cooling altogether, and to largely eliminate the need for heating even in cold climates. That is, energy savings can approach $100 \%$, not through improved device efficiencies, but by drastically reducing what mechanical devices are required to do. Passive heating, cooling, and ventilation systems are extensively reviewed in (1, Chapters 4, 6, and 8), so only some of the key system-related elements and interactions are outlined here.

Passive ventilation can be achieved through building designs that permit crossventilation and create wind suction; or that exploit the "stack" effect (the natural tendency of warm air to rise) through solar chimneys, stairwells, and atria; or that make use of air-flow windows, double-skin façades, and cool towers. Solar chimneys are tall open columns that are heated by the sun, creating a rising plume of warm air that draws outside air into and through the building. An early example (built in 1982) is provided by the solar chimneys on the south façade of the British Research Establishment office building in Garston, illustrated in Figure 8. Passive ventilation not only reduces energy use, but can improve air quality (if the outdoor air is not overly polluted!) and gives people what they generally want (a connection to the outside).

Inasmuch as a building's internal temperature will tend to be several degrees warmer than the outside air, there will be times when cooling is called for and the outside air is cool enough to provide the required cooling. Passive ventilation, by inducing the flow of outside air through the building, will thus provide some or all of the required cooling. During winter, ventilation air may need to be preheated. This can be done if passive ventilation systems are designed to draw outside air through the gap in a double-skin façade or through an airflow window. The incoming air will be preheated by picking up heat that would otherwise be lost to the outside and also (during the daytime) by picking up solar heat. Airflow windows can be designed to operate in different modes in summer and winter, as illustrated in Figure 9. 

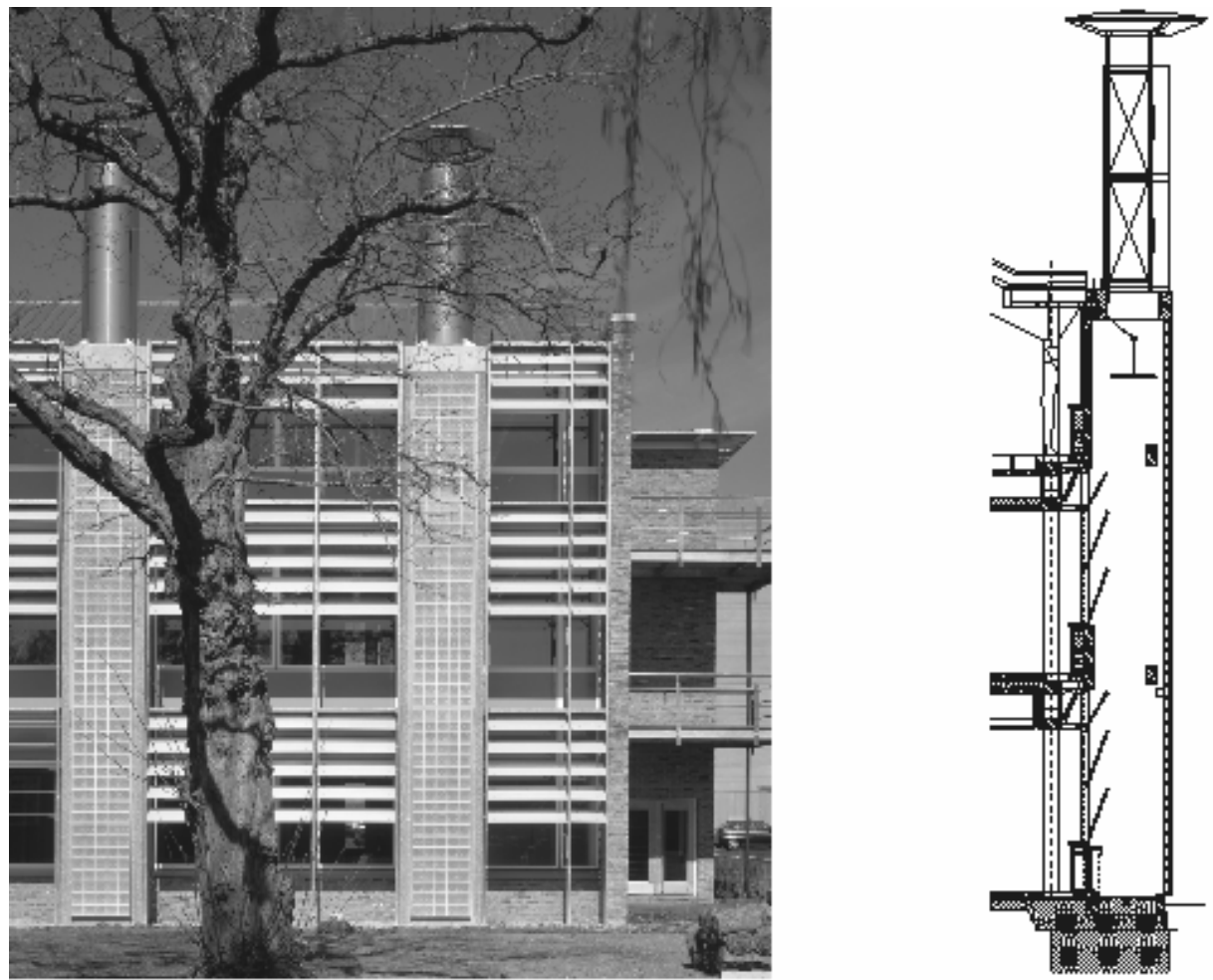

FIGURE 8. View of two solar chimneys and intervening glazed section with external shading louvres on the south façade of the British Research Establishment office building in Garston (UK) (left), cross section of the solar chimney in the British Research Establishment offices (middle) and of the glazed portion of the façade between the solar chimneys (right). Photographer: Dennis Gilbert, London. Source of diagram: (13).

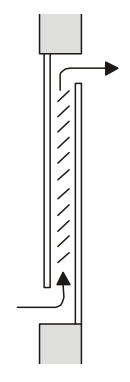

Supply-Air Window

Outdoor-to-Indoor Flow Winter Heating
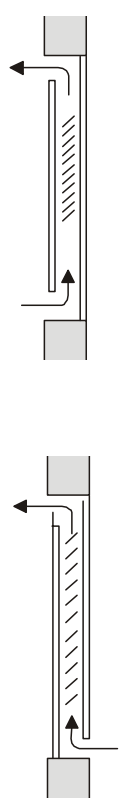

Supply-Air Window

Outdoor-to-Outdoor Flow Summer Cooling

\section{Exhaust-Air Window}

Indoor-to-Outdoor Flow Summer Ventilation

FIGURE 9. An airflow window that functions as a counterflow heat exchanger. Source: (1). 
Alternatively, ventilation air can be pre-warmed (in winter, and pre-cooled in summer) by drawing it through underground pipes. Note that the thermal driving force for passive ventilation is related to the difference between the interior and ambient temperatures, which will be largest in winter.

In hot climates, thermal insulation alone is of little benefit in reducing cooling requirements, especially if applied internally, because it can inhibit heat loss at night. Thermal mass reduces the rate of temperature change, and so can greatly attenuate the amplitude of internal temperature variations associated with high frequency (i.e., diurnal) external temperature variations. However, thermal mass is of little use after an extended warm period. However, the combination of external insulation, internal thermal mass, and night ventilation to remove heat from the thermal mass, can be very effective in reducing cooling loads. External insulation in this case serves to inhibit the daytime penetration of heat from outside, but does not inhibit night-time heat rejection because the insulation is bypassed through direct ventilation of the building interior with relatively cool night air. Thus, in the absence of aggressive night ventilation and exterior insulation, high thermal mass in hot climates can be a liability in that it slows the cooling of the building at night (this is especially an issue for residential buildings), but in the presence of strong night ventilation, thermal mass is an asset because it minimizes the daytime temperature rise. Thermal mass is an asset during the winter in cold climates because it allows greater passive absorption of solar thermal energy without overheating, and the absorbed heat can be slowly released at night. Thermal mass is more effective if indoor temperatures are allowed to float, as this permits more effective charging and discharging of the thermal mass. This in turn requires adoption of an 'adaptive' thermal comfort standard, in which the target interior temperature is allowed to vary with the outdoor air temperature rather than being fixed during the day and year round (this issue is discussed further later).

\section{LIGHTING SYSTEMS}

Lighting systems provide another example where system-level considerations and especially human behavior can provide large savings, in this case comparable to the large (factor of two) savings that can be achieved improved energy-using devices (lamps and ballasts). System-level considerations involve: a mix of task and ambient lighting (lower background lighting levels, with individually-controlled, greater levels of lighting when and where it is needed); incorporation of daylighting with light sensors, occupancy sensors, and dimmable electric lighting so that electric lighting levels can actually be varied according to the sunlight contribution and automatically turned off when a space is unoccupied; and wiring of lighting controls to coincide with zones having different degrees of daylighting. These issues are extensively discussed in Harvey (2006, Chapter 9) and in many references therein.

Building form and glazing area can significantly affect the extent to which daylighting can replace electric lighting, but this also has implications for heating and cooling loads. Thus, lighting energy use should not be analyzed in isolation, but as part of an optimized system of overall energy use. Computer algorithms to automatically control adjustable shading devices can be designed to minimize the sum 
of lighting plus cooling energy use for a given building, occupancy schedule, and climate. If only the amount of daylight needed for a given task is allowed to enter a building, cooling energy requirements will be reduced compared to the use of electric lighting, adding to the energy savings from reduced electric lighting loads. Peak electrical and cooling loads are also reduced, allowing downsizing of cooling systems and electrical transformers, thereby reducing costs.

It appears that most people require less light at night and on cloudy days, because of less window glare but also because requirements are conditioned in part by expectations (14). This parallels the finding that the acceptable temperature range depends in part on expectations, which vary with outside conditions. An added benefit of task/ambient lighting, then, is that it allows the lighting level to be adjusted to changing preferences, as well as to differences between users.

\section{RECIRCULATION-LOOP DOMESTIC HOT-WATER SYSTEMS}

Recirculation-loop (RL) domestic hot-water systems provide another example of dramatic energy savings that can be achieved at the system level, with no change in the efficiency of individual devices (hot-water boilers and pumps in this case). In RL systems, water is heated and stored in a central tank, continuously circulated through a closed loop to all the points of use, and consumed as needed. This keeps the hot-water pipes warm, so that hot water is instantly available when the faucet is opened. Apart from convenience, this avoids wasting hot water by running the faucet until the pipes have warmed sufficiently to deliver hot water to the faucet. Since the purpose of recirculation is to keep the pipes warm, the required flow can be reduced by insulating the pipes well. Since pumping power varies with the flow rate to the third power, dramatic reductions in pump energy use are possible along with reduced heat loss. However, even with well-insulated piping, piping heat losses can constitute $40 \%$ to more than $50 \%$ of the total hot-water load $(15,16)$. An alternative is point-of-use water (POU) heaters, in which water heaters are located at or very close to the point of use.

Hiller et al. (17) monitored the energy use in a new (1997 opening) school in Tennessee using an RL system serving six points of use, and again after it was converted to a POU system with three water heaters and short piping. An impressive 91\% savings in total (pump+water heater) energy use was achieved. The POU water heaters were operated continuously, but it is estimated that they could have been shut down at night, on weekends, and during school holidays, with a further energy savings of $40 \%$ (bringing the total savings to $94.3 \%$ ).

\section{HUMANS AS PART OF THE ENERGY-USING SYSTEM}

Humans are a critical part of the building energy systems, especially where passive ventilation and daylighting are part of the building, and with regard to the control of HVAC systems. In particular, adoption of an adaptive thermal comfort standard - in which the indoor temperature is allowed to vary with the outdoor temperature - can save substantial amounts of energy. Fortunately, it turns out that the indoor temperature perceived as "comfortable" increases with increasing outdoor 
temperature. Thus, buildings do not need to be cooled to as low a temperature on the hottest days of the year as on other days. Furthermore, a large body of evidence indicates that the temperature and humidity set-points in general are significantly lower than necessary $(18,19)$. Increasing the thermostat from $24^{\circ} \mathrm{C}$ to $28^{\circ} \mathrm{C}$ in summer will reduce annual cooling energy use by more than a factor of three for a typical office building in Zurich and by more than a factor of two in Rome (20). The temperatures deemed to be acceptable on hot days are 1-2 K warmer in buildings with natural ventilation than in buildings with mechanical ventilation, thereby extending the range of ambient conditions under which mechanical cooling can be avoided in passively ventilated buildings.

\section{IMPLICATIONS: THE NEED FOR AN INTEGRATED DESIGN PROCESS}

This paper has illustrated some of the many ways in which dramatic energy savings can be achieved in buildings by treating buildings as systems - savings that are many times greater than what can be achieved through improved device efficiencies. However, the conventional process of designing a building is a linear process, in which the architect makes a number of design decisions without extensive or even any consideration of their energy implications, and then passes on the design to the engineers, who are supposed to make the building habitable through mechanical systems. The design of mechanical systems, however, is also largely a linear process with, in some cases, system components specified without yet having all of the information needed in order to design an efficient system (given the constraints imposed by the architect) (21).

What is required is an alternative design process, referred to as the Integrated Design Process (IDP). This is not to say that there is no integration or teamwork in the traditional design process, but rather, that the integration is not normally directed toward minimizing total energy use through an iterative modification of a number of alternative initial designs and concepts so as to optimize the design as a whole (rather than optimizing individual subsystems). Two steps in the design process can be said to be "integrated" if the effect of the first design decision on the second design decision is taken into account when making the first design decision. The greater the number of design decisions that are linked in this way, the more "integrated" is the design. Integrated design means, as a minimum, to consider the impact of a change in early design decisions such as building shape and orientation, envelope characteristics, and inclusion of heat recovery on subsequent decisions, such as the nature and sizing of mechanical systems.

A number of early alternative choices should be considered as part of the IDP, with the goal of minimizing some objective criterion such as lifecycle cost, net present value of capital and operating costs, or energy cost alone subject to some upper limit concerning the acceptable payback time. If this is complemented by the choice of the most efficient equipment available, optimization of the equipment operation, and commissioning to ensure that everything works as intended, then savings on the order of $35-50 \%$ can be achieved relative to conventional practice for new buildings. This is 
the most basic IDP, a simple "back-to-basics" approach that stresses a quality envelope, quality equipment, and quality sizing and operation of mechanical equipment. Buildings produced in this way are still conventional buildings, but computer simulation will be needed if one wants to optimize the design choices.

To push the savings beyond the 35-50\% achievable through a "back-to-basics" approach, an increasing number of unconventional measures will need to be carefully combined - measures such as passive ventilation, heating, and cooling involving perhaps double-skin façades and airflow windows; thermal mass with night ventilation; chilled ceiling, displacement ventilation, and desiccant dehumidification; daylighting; and adaptive thermal comfort. Computer simulation involving simulation specialists who serve as a liaison between the architects and engineers is essential. The integrated design process entails two-way interactions between the client and design team, between the architect and engineers, and between the design team and the contractors. Once the design is complete, the design team must be available during construction to explain details that are not clear, because no matter how thorough the plans and specifications, some details that affect the energy use by the building will be overlooked. The integrated design process in a number of buildings in Europe and North America is discussed in some detail, along with lessons learned, in IEA (22, 23).

de Wilde and van der Voorden (24) present a strategy for the selection of energysaving components during the building design process. This strategy draws upon principles of systems engineering and decision theory. The elements of the strategy are:

- To define an option space, consisting of different energy-savings combinations that are to be considered.

- To identify all the performance characteristics (dimensions) of all the design options, in order to determine a set of criteria for the selection of the preferred option.

- $\quad$ To specify objectives, constraints, and performance indicators.

- $\quad$ To predict the performance of the design options, primarily using computer tools but possibly also using experimental set-ups.

- To evaluate the predicted performance, based on how well each option performs in the various performance dimensions, with some weighting of the different performance dimensions.

Computer simulation is needed when designing a high-performance building in order to be able to assess, in advance, the impacts on energy use of alternative designs and in order to be able to determine the optimum design for a given building in a given climate. In conventional practice, simulation is used only for the final confirmation of the performance of the mechanical system, rather than as an integrated element of the design process. For building simulation software to lead to improved designs, it must be easy to use in a comparative mode, that is, to be able to systematically generate alternative designs by varying input parameters and to generate an n-dimensional design-performance space. Current simulation environments do not support this process (25). For further information on building energy simulation tools and their use 
in the design profession, the interested reader can consult the detailed review by Jacobs and Henderson (26). For information on 291 building software tools, see the US DOE Energy Efficiency and Renewable Energy website (www.eere.doe.gov/buildings/tools_directory).

\section{OPPORTUNITIES FOR PHYSICISTS}

There are a number of system-related considerations that may be of interest to physicists wanting to move into the building energy-efficiency field. These include:

- computational fluid dynamics (CFD) to simulate passive ventilation or hybrid passive-mechanical systems;

- optical properties of windows with regard to passive solar gain, minimization of cooling loads, maximization of daylighting opportunities;

- $\quad$ research pertaining to phase-change materials and thermal mass; and

- $\quad$ all elements of building energy simulation.

\section{REFERENCES}

1. L.D.D. Harvey, A Handbook on Low-Energy Buildings and District-Energy Systems: Fundamentals, Techniques and Examples. EarthScan, London, 701 pages (2006).

2. N. Bourassa, P. Haves, and J. Huang, "A computer simulation appraisal of non-residential low energy cooling systems in California," in Proceedings of the 2002 ACEEE Summer Study on Energy Efficiency in Buildings, vol. 3, American Council for an Energy Efficient Economy, Washington, pp. 41-53 (2002).

3. M. Howe, D. Holland, and A. Livchak, "Displacement ventilation-Smart way to deal with increased heat gains in the telecommunication equipment room," ASHRAE Transactions 109(Part 1), 323-327 (2003).

4. $\quad$ S.A. Mumma, "Ceiling panel cooling system," ASHRAE Journal vol. 43(11), 28-32 (2001).

5. F. Sodec, "Economic viability of cooling ceiling systems," Energy and Buildings, vol. 30, 195201 (1999).

6. B. Costelloe and D. Finn, "Indirect evaporative cooling potential in air-water systems in temperate climates," Energy and Buildings, vol. 35, 573-591 (2003).

7. K.J. Loudermilk, "Underfloor air distribution solutions for open office applications," ASHRAE Transactions vol. 105 (Part 1), 605-613 (1999).

8. M.J. Brandemuehl and J.E. Braun, "The impact of demand-controlled and economizer ventilation strategies on energy use in buildings," ASHRAE Transactions vol. 105(Part 2), 3950 (1999).

9. J.C. Fischer, J.R. Sand, B. Elkin, and K. Mescher, "Active desiccant, total energy recovery hybrid system optimizes humidity control, IAQ, and energy efficiency in an existing dormitory facility," ASHRAE Transactions vol. 108(Part 2), 537-545 (2002).

10. S.A. Mumma and K.M. Shank, "Achieving dry outside air in an energy-efficient manner," ASHRAE Transactions vol. 107(Part 1), 553-561 (2001).

11. J.L. Niu, L.Z. Zhang, and H.G. Zuo, "Energy savings potential of chilled-ceiling combined with desiccant cooling in hot and humid climates," Energy and Buildings vol. 34, 487-405 (2002).

12. A. Egan, "Reasons, results, and remedies for pump safety factors overuse," ASHRAE Transactions, vol. 107(Part 2), 559-565 (2001). 
13. W. Gething, "The Environmental Building: The Building Research Establishment, Watford," in Green Buildings Pay, edited by B. Edwards, London, Spon Press, pp. 86-93 (2003).

14. P.A. Torcellini, M. Deru, B. Griffith, N. Long, S. Pless, R. Judkoff, and D.B. Crawley, "Lessons learned from field evaluation of six high-performance buildings," in Proceedings of the 2004 ACEEE Summer Study on Energy Efficiency in Buildings, vol. 3, American Council for an Energy Efficient Economy, Washington, pp. 325-337 (2004).

15. F.S. Goldner, "Control strategies for domestic hot water recirculation systems," ASHRAE Transactions, vol. 105(Part 1), 1030-1046 (1999).

16. J.D. Lutz, G. Klein, D. Springer, and B.D. Howard, "Residential hot water distribution systems: Roundtable session," in Proceedings of the 2002 ACEEE Summer Study on Energy Efficiency in Buildings, vol. 1, American Council for an Energy Efficient Economy, Washington, pp. 131-144 (2002).

17. C.C. Hiller, J. Miller, and D.R. Dinse, "Field test comparison of hot water recirculation loop vs. point-of-use water heaters in a high school," ASHRAE Transactions, vol. 108(Part 2), 771779 (2002).

18. R.J. de Dear and G.S. Brager, "Developing an adaptive model of thermal comfort and preference," ASHRAE Transactions, vol. 104(Part 1), 145-167 (1998).

19. M.E. Fountain, E. Arens, T. Xu, F.S. Bauman, and M. Oguru, "An investigation of thermal comfort at high humidities," ASHRAE Transactions, vol. 105, 94-103 (1999).

20. P. Jaboyedoff, C.-A. Roulet, V. Dorer, A. Weber, and A. Pfeiffer, "Energy in air-handling units--results of the AIRLESS European project," Energy and Buildings, vol. 36, 391-399 (2004).

21. M. Lewis, "Integrated design for sustainable buildings," Building for the Future, A Supplement to ASHRAE Journals, vol. 46(9), 22-30 (2004).

22. IEA (International Energy Agency), Examples of Integrated Design: Five Low Energy Buildings Created Through Integrated Design, International Energy Agency, Solar Heating and Cooling Programme, Task 23, Paris (2000). Available from www.iea-shc.org/task23.

23. IEA (International Energy Agency), The Integrated Design Process in Practice: Demonstration Projects Evaluated, International Energy Agency, Solar Heating and Cooling Programme, Task 23, Paris (2002). Available from www.iea-shc.org/task23.

24. P. de Wilde and M. van der Voorden, "Providing computational support for the selection of energy saving building components," Energy and Buildings, vol. 36, 749-758 (2004).

25. A. Mahdavi and B. Gurtekin, "Computational support for the generation and exploration of the design-performance space," in Seventh International IBPSA Conference, Rio de Janeiro, Brazil, pp. 669-676 (13-15 August 2001). Available from www.ibpsa.org.

26. P. Jacobs and H. Henderson, State-of-the-Art Review: Whole Building, Building Envelope, and HVAC Component and System Simulation and Design Tools, prepared for the AirConditioning and Refrigeration Technology Institute, Arlington, Virginia (2002). Available from www.archenergy.com. 